\title{
Metabolic Syndrome in Patients With Ankylosing Spondylitis
}

\author{
Ibrahim Batmaz ${ }^{\mathrm{a}}$, Mehmet Karakoc ${ }^{\mathrm{a}}$, Mustafa Akif Sariyildiz ${ }^{\mathrm{a}, \mathrm{d}}$, Selma Yazici \\ Mehmet Tahtasiz ${ }^{\mathrm{a}}$ Zuhal Atilgan ${ }^{\mathrm{c}}$, Remzi Cevik ${ }^{\mathrm{a}}, \mathrm{Kemal} \mathrm{Nas}^{\mathrm{a}}$
}

\begin{abstract}
Background: The objective of this study is to investigate the presence of metabolic syndrome (MS) in patients with ankylosing spondylitis (AS) and to evaluate its relationship with the clinical parameters.
\end{abstract}

Methods: Fifty patients who presented to the Dicle University School of Medicine, Physical Therapy and Rehabilitation Outpatient Clinic and were diagnosed with AS according to the 1984 New York criteria were enrolled in this study. The control group consisted of 44 healthy control subjects. Assessment of the MS was made according to the diagnostic criteria specified in the National Cholesterol Education Program Adult Treatment Panel III Report (NCEP ATP III). Functional status and disease activity were evaluated using the Bath Ankylosing Spondylitis Functional Index (BASFI) and the Bath Ankylosing Spondylitis Disease Activity Index (BASDAI) for AS.

Results: MS was observed in 6 out of the $50 \mathrm{AS}$ patients (12\%) and in 2 out of the 44 controls $(4.5 \%)(\mathrm{P}>0.05)$. However, the HDL cholesterol level $(\mathrm{P}=0.006)$ was found as significantly lower in AS patients than the controls. No statistically significant differences were observed in the disease duration and functional and clinical activity indices between the AS patients with and without MS.

Conclusions: Although the frequency of MS was observed to be

Manuscript accepted for publication December 14, 2011

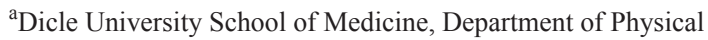
Medicine and Rehabilitation, Diyarbakir, Turkey

${ }^{\mathrm{b}}$ Izzet Baysal University School of Medicine, Department of Physical

Medicine and Rehabilitation, Bolu, Turkey

${ }^{c}$ Dicle University School of Medicine, Departments of Cardiology, Diyarbakir, Turkey

${ }^{\mathrm{d}}$ Corresponding author: Mustafa Akif Sariyildiz.

Email: makifsariyildiz@hotmail.com

doi:10.4021/jem61e higher in patients with AS than the controls in this study, the differences were statistically insignificant between the two groups.

Keywords: Ankylosing spondylitis; Metabolic syndrome

\section{Introduction}

Ankylosing spondylitis (AS) is a chronic inflammatory disease of unknown etiopathogenesis, which especially involves the axial skeletal system although it may also affect the peripheral joints and the extra-articular structures [1,2]. The mortality and morbidity rates in AS patients are higher in comparison to the general population. In chronic rheumatic diseases, mortality due to cardiovascular (CVS) reasons shows an increase. This ratio has been observed as $20 \%$ to $40 \%$ in patients with AS [3-5]. It has also been reported that cardiac involvement may occur in AS without showing any clinical symptoms and therefore these findings must be observed even during the asymptomatic phase [5-8].

Metabolic syndrome (MS) is the clinical condition where risk factors for the development of cardiovascular diseases and diabetes mellitus accumulate [9]. Certain studies point to the relationship between the metabolic syndrome and the inflammation $[10,11]$. Compared to the general population, the prevalence of MS has been reported to be significantly increased in patients with inflammatory diseases like rheumatoid arthritis, psoriasis or AS [12-16].

Therefore, we set out to investigate the frequency and components of MS, which paves the way to cardiovascular diseases and has recently gained more importance in patients with AS, together with the relationship between MS and the disease activity.

\section{Materials and Methods}

Fifty patients who presented to the Dicle University School of Medicine, Department of Physical Medicine and Rehabilitation outpatient clinic and were diagnosed with definite AS according to the 1984 Modified New York Criteria [17] 
Table 1. Demographic Features and Laboratory Findings of the AS and Control Groups

\begin{tabular}{llll}
\hline & Number of patients $(\mathbf{n}=\mathbf{5 0})$ & Controls $(\mathbf{n}=\mathbf{4 4})$ & P \\
\hline Age & $34.14 \pm 8.85$ & $31.61 \pm 8.95$ & NS \\
Sex $(\mathrm{M} / \mathrm{F})$ & $40 / 10$ & $35 / 9$ & $\mathrm{NS}$ \\
CRP $(\mathrm{mg} / \mathrm{dL})$ & $2.1 \pm 3.66$ & $0.28 \pm 0.18$ & 0.001 \\
ESR $(\mathrm{mm} / \mathrm{h})$ & $16.08 \pm 20.71$ & $5.7 \pm 4.72$ & 0.02 \\
Leukocytes & $8.06 \pm 2.64$ & $6.18 \pm 1.12$ & 0.001 \\
Platelets & $264.69 \pm 75.66$ & $222.02 \pm 66.28$ & 0.005 \\
Erythrocytes & $4.97 \pm 0.54$ & $4.66 \pm 0.48$ & 0.005 \\
Total cholesterol $(\mathrm{mg} / \mathrm{dL})$ & $175.89 \pm 37.9$ & $157.7 \pm 27.17$ & NS \\
LDL cholesterol $(\mathrm{mg} / \mathrm{dL})$ & $100.5 \pm 80.28$ & $97.27 \pm 24.17$ & $\mathrm{NS}$ \\
\hline
\end{tabular}

LDL: Low density lipoprotein; CRP: C-reactive protein; NS: not significant $(P>0.05)$

were enrolled in our study. The control group consisted of 44 healthy individuals of matching age and sex groups who presented to our clinic with non-specific back pain. All the patients were given information about the study before they were presented with informed consent forms to fill out and sign. The approval of the local ethics committee was obtained prior to the initiation of the study.

Patients with any kind of collagen tissue disorders or other inflammatory articular diseases, malignancies, diseases of the central nervous system, chronic kidney disease, chronic liver disease and thyroid diseases besides AS, and those who were pregnant were excluded from the study.

After the detailed patient histories were obtained, all the patients underwent detailed systemic examinations and locomotor system screenings. The waist circumference was measured with a tape measure at the slimmest point of the waist below the lower costal margin while the patient was standing upright naked from the waist up. The systolic and diastolic blood pressure values were measured from the right arm in due manner between 9.00 and 12.00, after the patients rested for 30 minutes in sitting position.

The laboratory tests included the $\mathrm{CBC}$, erythrocyte sedimentation rate (ESR), C-reactive protein (CRP), routine biochemistry tests, lipid profile and HLA B27. The patients were advised to fast after 20.00 on the night before the day of the blood tests. The venous blood samples were tested without delay.

In order to diagnose MS, the most commonly preferred criteria are those defined in the National Cholesterol Education Program Adult Treatment Panel III Report (NCEP-

Table 2. MS Component Values of the AS and Control Groups

\begin{tabular}{llll}
\hline & $\begin{array}{l}\text { Ankylosing spondylitis } \\
(\mathbf{n}=\mathbf{5 0})\end{array}$ & $\begin{array}{l}\text { Controls } \\
(\mathbf{n}=\mathbf{4 4})\end{array}$ & P \\
\hline Waist circumference (cm) & $88.4 \pm 14.54$ & $82.75 \pm 13.14$ & NS \\
Systolic blood pressure (mmHg) & $115.3 \pm 0.46$ & $116.93 \pm 10.3$ & NS \\
Diastolic blood pressure (mmHg) & $73.2 \pm 9.24$ & $75.7 \pm 7.77$ & NS \\
HDL cholesterol (mg/dL) & $43.97 \pm 10.16$ & $49.62 \pm 9.14$ & 0.006 \\
Triglycerides (mg/dL) & $147.17 \pm 80.28$ & $124.39 \pm 46.7$ & NS \\
Fasting blood glucose (mg/dL) & $93.32 \pm 10.7$ & $93.18 \pm 19.42$ & NS \\
MS (\% present) & $6(12)$ & $2(4.5)$ & NS \\
\hline
\end{tabular}

HDL: High density lipoprotein; MS: Metabolic Syndrome; NS: not significant $(P>0.05)$ 
Table 3. MS (+) AS and MS (-) AS Demographic Features and Laboratory Findings

\begin{tabular}{llll}
\hline & AS/MS (+) & AS/MS (-) & P \\
\hline Age & $39.83 \pm 4.87$ & $33.36 \pm 9.02$ & NS \\
VAS & $3.66 \pm 2.58$ & $3.19 \pm 2.68$ & NS \\
BASDAI & $2.91 \pm 1.77$ & $2.28 \pm 1.8$ & NS \\
BASFI & $28.66 \pm 29.95$ & $22.86 \pm 23.22$ & NS \\
HAQ & $0.97 \pm 0.9$ & $0.63 \pm 0.76$ & NS \\
Disease duration (years) & $11 \pm 8.07$ & $6.31 \pm 4.68$ & NS \\
CRP (mg/dL) & $2.32 \pm 3.21$ & $2.07 \pm 3.76$ & NS \\
Leukocyte & $8.5 \pm 2.38$ & $8.1 \pm 2.69$ & NS \\
ESR (mm/h) & $22.33 \pm 32.5$ & $15.21 \pm 18.93$ & NS \\
\hline
\end{tabular}

VAS: Visual analogue (pain) score; BASDAI: Bath Ankylosing Spondylitis Disease Activity Index; BASFI: Bath Ankylosing Spondylitis Functional Index; CRP: C-reactive protein; NS: not significant $(P>0.05)$

ATP III) [18]. We also based our study on the NCEP-ATP III criteria and diagnosed those patients with MS, who tested positive for 3 or more out of the following 5 risk factors: Waist circumference (female $>88 \mathrm{~cm}$, male $>102 \mathrm{~cm}$ ), triglycerides $\geq 150 \mathrm{mg} / \mathrm{dL}$, HDL cholesterol (female $<50 \mathrm{mg}$ / $\mathrm{dL}$, male $<40 \mathrm{mg} / \mathrm{dL})$, blood pressure $(\geq 130 / 85 \mathrm{mmHg})$ and fasting blood glucose $(\geq 110 \mathrm{mg} / \mathrm{dL})$.

The disease activities of our patients were evaluated based on the Bath Ankylosing Spondylitis Disease Activity Index (BASDAI), while their functional statuses were assessed according to the Bath Ankylosing Spondylitis Functional Index (BASFI) $[19,20]$. The reliability and validity of the Turkish version of BASDAI and BASFI have already been demonstrated [21,22].

The general health of the patients was assessed according to the Health Assessment Questionnaire (HAQ). The reliability and validity of the Turkish version of the HAQ have been studied by Kuçukdeveci et al [23].

The statistical analysis was performed using the SPSS 16.0 software package. The compliance of the variables to the normal distribution was assessed through the Kolmogorov-Smirnov test. The inter-group differences were evaluated using the Student's t-test. While the categorical and ratioproportional variables were assessed through the Chi-square test, the inter-variable relationships were evaluated with the help of Pearson's correlation test. Statistical significance was based on a value of $\mathrm{P}<0.05$.

\section{Results}

Both the AS and the control groups were similar in terms of age distribution $(\mathrm{P}>0.05)$. The laboratory parameters CRP, ESR, leukocyte count, platelet count and erythrocyte count were higher in the patient group in comparison to the control group and this difference was statistically significant (Table 1). Although the total cholesterol and LDL cholesterol values were observed to be higher in the patient group compared to the control group, the difference was not statistically significant $(\mathrm{P}>0.05)$.

MS was observed in $12 \%$ (6 in 50) of the patients with AS and in 4.5\% (2 in 44) of the controls. The difference between them was statistically insignificant $(\mathrm{P}>0.05)$. We have found the HDL cholesterol levels significantly higher in the control group compared to the AS group $(\mathrm{P}=0.006)$. However, we have observed similar values with the control group in terms of the other MS components like systolic and diastolic blood pressure, fasting blood glucose and waist circumference $(\mathrm{P}>0.05)$ (Table 2).

AS patients with or without MS were divided into two groups and were compared in terms of the CRP, leukocyte, ESR, disease duration, VAS, BASDAI, BASFI and HAQ assessments. No statistically significant difference has been observed between the two groups $(\mathrm{P}>0.05)$ (Table 3$)$.

\section{Discussion}

In this study where we investigated the frequency of MS in patients with AS, we have observed the rate of MS in the AS patients higher than the control group. However, the results were statistically insignificant. No significant relationship in terms of disease duration and functional or clinical activity was observed between the AS patients with MS and those 
without MS.

In the study they conducted, Malesci et al have observed that the rate of MS in patients with AS was higher than the controls. While $45.8 \%$ of the AS patients in their study was found to have MS, this ratio in the control group was $10.5 \%$. They have also observed that where the systolic blood pressure, LDL cholesterol, triglycerides and total cholesterol levels were higher in patients with AS in comparison to the controls, the HDL-cholesterol levels were lower. Still, the investigators have not detected any statistically significant relationship between the presence of MS in the AS patients and their ages, disease duration and BASDAI and BASFI results [16]. In our study, we have also observed the HDL cholesterol values in the patients with AS to be statistically significantly lower than the controls. In a study by Mathieu et al, the HDL cholesterol levels in patients with AS were also found to be lower than the control group. It has also been reported in the same study that the risk of myocardial infarction in the AS patients was observed to be higher compared to the controls, and this has been attributed to the atherogenic lipid profile or the systemic inflammation [24]. In another study, the lower HDL cholesterol values were observed to be correlated with the intensity of the inflammation [25]. Van Eijk et al have observed in their study that the increases in the sedimentation rate and CRP values caused significant decreases in the HDL cholesterol levels [26]. Based on these results, it can be concluded that the cause of the lower HDL values in the patients with AS may play a partial role in the inflammation and the cardiovascular diseases.

Papadakis et al have also found the prevalence of MS in patients with AS higher than the control group. They have also observed that the AS patients with MS are older than the AS patients without MS; their disease duration was longer and they had higher BASDAI scores and cardiovascular risks [15]. However, Mok et al determined in their study that there was no increase in the MA frequency in the AS group in comparison to the control group [27]. Also in our study, although we have observed higher MS rates in the patients with AS than the controls, the results were statistically insignificant. We did not observe any statistically significant relationship between the presence of MS and the disease duration, the BASDAI and the BASFI values. These results were also in compliance with the data in the literature.

In conclusion, we did not detect any significant increase in the frequency of MS in the patients with AS compared to the control group.

\section{Limitations of the study}

The most prominent limitation of our study was the lack of investigation in the patients with MS in terms of any cardiovascular involvement. If the presence and state of any cardiovascular involvement in patients with AS had been studied and the related observations were compared with
MS, the effect of MS in the patients with AS on cardiovascular involvement would have been discussed in greater extent. Also, the limited number of the study population was another factor hindering accurate results. Further and wider ranging clinical studies are thus needed in order to evaluate the presence of MS in patients with AS.

\section{References}

1. Khan MA. Ankylosing spondylitis: clinical features. In: Klippel J, Dieppe P, eds. Rheumatology, 2nd edn. London: Mosby-Wolfe, 1998. p.10-6.

2. Karatay S. Ankilozan Spondilit Hastalarında Beslenme ve Diyet Modifikasyonları. Turkiye Klinikleri J Immunol Rheumatol-Special Topics 2011; $4: 86-88$.

3. Kaprove RE, Little AH, Graham DC, Rosen PS. Ankylosing spondylitis: survival in men with and without radiotherapy. Arthritis Rheum. 1980;23(1):57-61.

4. Lehtinen K. Mortality and causes of death in 398 patients admitted to hospital with ankylosing spondylitis. Ann Rheum Dis. 1993;52(3):174-176.

5. Lautermann D, Braun J. Ankylosing spondylitis--cardiac manifestations. Clin Exp Rheumatol. 2002;20(6 Suppl 28):S11-15.

6. Demiralp E, Kardesoglu E, Kiralp MZ, Cebeci BS, Keskin I, Ozmen N, Dursun H. Aortic elasticity in patients with ankylosing spondylitis. Acta Cardiol. 2004;59(6):630-634.

7. Yildirir A, Aksoyek S, Calguneri M, Oto A, Kes S. Echocardiographic evidence of cardiac involvement in ankylosing spondylitis. Clin Rheumatol. 2002;21(2):129134.

8. Crowley JJ, Donnelly SM, Tobin M, FitzGerald O, Bresnihan B, Maurer BJ, Quigley PJ. Doppler echocardiographic evidence of left ventricular diastolic dysfunction in ankylosing spondylitis. Am J Cardiol. 1993;71(15):1337-1340.

9. Grundy SM, Brewer HB, Jr., Cleeman JI, Smith SC, Jr., Lenfant C. Definition of metabolic syndrome: Report of the National Heart, Lung, and Blood Institute/American Heart Association conference on scientific issues related to definition. Circulation. 2004;109(3):433-438.

10. Rutter MK, Meigs JB, Sullivan LM, D’Agostino RB, Sr., Wilson PW. C-reactive protein, the metabolic syndrome, and prediction of cardiovascular events in the Framingham Offspring Study. Circulation. 2004;110(4):380385 .

11. Ridker PM, Wilson PW, Grundy SM. Should C-reactive protein be added to metabolic syndrome and to assessment of global cardiovascular risk? Circulation. 2004;109(23):2818-2825.

12. Chung CP, Oeser A, Solus JF, Avalos I, Gebretsadik T, Shintani A, Raggi P, et al. Prevalence of the metabolic 
syndrome is increased in rheumatoid arthritis and is associated with coronary atherosclerosis. Atherosclerosis. 2008;196(2):756-763.

13. Chen YJ, Wu CY, Shen JL, Chu SY, Chen CK, Chang YT, Chen CM. Psoriasis independently associated with hyperleptinemia contributing to metabolic syndrome. Arch Dermatol. 2008;144(12):1571-1575.

14. Cohen AD, Sherf M, Vidavsky L, Vardy DA, Shapiro J, Meyerovitch J. Association between psoriasis and the metabolic syndrome. A cross-sectional study. Dermatology. 2008;216(2):152-155.

15. Papadakis JA, Sidiropoulos PI, Karvounaris SA, Vrentzos GE, Spanakis EK, Ganotakis ES, Kritikos HD, et al. High prevalence of metabolic syndrome and cardiovascular risk factors in men with ankylosing spondylitis on anti-TNFalpha treatment: correlation with disease activity. Clin Exp Rheumatol. 2009;27(2):292-298.

16. Malesci D, Niglio A, Mennillo GA, Buono R, Valentini G, La Montagna G. High prevalence of metabolic syndrome in patients with ankylosing spondylitis. Clin Rheumatol. 2007;26(5):710-714.

17. van der Linden S, Valkenburg HA, Cats A. Evaluation of diagnostic criteria for ankylosing spondylitis. A proposal for modification of the New York criteria. Arthritis Rheum. 1984;27(4):361-368.

18. Executive Summary of The Third Report of The National Cholesterol Education Program (NCEP) Expert Panel on Detection, Evaluation, And Treatment of High Blood Cholesterol In Adults (Adult Treatment Panel III). JAMA. 2001;285(19):2486-2497.

19. Garrett S, Jenkinson T, Kennedy LG, Whitelock H, Gaisford P, Calin A. A new approach to defining disease status in ankylosing spondylitis: the Bath Ankylosing Spondylitis Disease Activity Index. J Rheumatol. 1994;21(12):2286-2291.

20. Calin A, Garrett S, Whitelock H, Kennedy LG, O’Hea
J, Mallorie P, Jenkinson T. A new approach to defining functional ability in ankylosing spondylitis: the development of the Bath Ankylosing Spondylitis Functional Index. J Rheumatol. 1994;21(12):2281-2285.

21. Akkoc Y, Karatepe AG, Akar S, Kirazli Y, Akkoc N. A Turkish version of the Bath Ankylosing Spondylitis Disease Activity Index: reliability and validity. Rheumatol Int. 2005;25(4):280-284.

22. Yanik B, Gursel YK, Kutlay S, Ay S, Elhan AH. Adaptation of the Bath Ankylosing Spondylitis Functional Index to the Turkish population, its reliability and validity: functional assessment in AS. Clin Rheumatol. 2005;24(1):41-47.

23. Kucukdeveci AA, Sahin H, Ataman S, Griffiths B, Tennant A. Issues in cross-cultural validity: example from the adaptation, reliability, and validity testing of a Turkish version of the Stanford Health Assessment Questionnaire. Arthritis Rheum. 2004;51(1):14-19.

24. Mathieu S, Gossec L, Dougados M, Soubrier M. Cardiovascular profile in ankylosing spondylitis: a systematic review and meta-analysis. Arthritis Care Res (Hoboken). 2011;63(4):557-563.

25. Divecha H, Sattar N, Rumley A, Cherry L, Lowe GD, Sturrock R. Cardiovascular risk parameters in men with ankylosing spondylitis in comparison with non-inflammatory control subjects: relevance of systemic inflammation. Clin Sci (Lond). 2005;109(2):171-176.

26. van Eijk IC, Peters MJ, Serne EH, van der Horst-Bruinsma IE, Dijkmans BA, Smulders YM, Nurmohamed MT. Microvascular function is impaired in ankylosing spondylitis and improves after tumour necrosis factor alpha blockade. Ann Rheum Dis. 2009;68(3):362-366.

27. Mok CC, Ko GT, Ho LY, Yu KL, Chan PT, To CH. Prevalence of atherosclerotic risk factors and the metabolic syndrome in patients with chronic inflammatory arthritis. Arthritis Care Res (Hoboken). 2011;63(2):195-202. 